\title{
Compound Gear Box Torque Analysis of Vertical Mixer
}

\author{
Guo Fang \\ School of Mechanical Science \& \\ Engineering,Huazhong University of \\ Science \& Technology \\ Wuhan, China \\ mimigaga168@126.com
}

\section{Li Yuan}

School of Mechanical Science \& Engineering,Huazhong University of Science \& Technology Wuhan, China

\author{
Li Xiwen \\ School of Mechanical Science \& \\ Engineering,Huazhong University of \\ Science \& Technology \\ Wuhan, China
}

Wang Wenyun

School of Mechanical Science \& Engineering,Huazhong University of Science \& Technology Wuhan, China

\author{
Xiong Hongxia \\ School of Mechanical Science \& \\ Engineering,Huazhong University of \\ Science \& Technology \\ Wuhan, China
}

\section{Zhang Yi}

School of Mechanical Science \& Engineering,Huazhong University of Science \& Technology

Wuhan, China

\begin{abstract}
The input and output torque of different shafts are important parameters in the design of vertical mixer's transmission agent. However, the calculation of the torque is so difficult because of the complex structure. In order to solve this problem, a relationship between input and output torque, number of gear teeth, rotation and revolution torque of compound gear box is established and the simulation by FLUENT of torque distribution is finished. Torque distribution is obtained by the calculation and simulation, which is useful to the design of vertical mixer.
\end{abstract}

\section{Keywords- Vertical mixer; torque; Compound gear box}

\section{INTRODUCTION}

Mixing exists everywhere ${ }^{[1]}$. In the areas of chemical, pharmaceutical, food, biotechnology and environmental industry, by the method of mixing, workers mix the material to reduce the non-uniformity of the material inside in order to change the physical or chemical properties of the hybrid materials to achieve the ultimate technological requirements ${ }^{[1]}$.

With the improvement of the production process requirements of high-viscosity materials, the vertical mixers need higher stability, security, reliability, easy for maintenance and operation. In order to achieve sufficient mixing of materials, confidential revolution and rotation movement of the mixer is needed. Therefore, a single input multi-output composite planetary gear is chosen to achieve the role of the stirring and mixing. Because it is a single-input multi-output system, even though we know the input torque, the relationship between pluralities of output torque cannot be calculated. And due to the structural limitations of the mixer, the revolution and the rotation torque measurement has set limit for the development of vertical mixer ${ }^{[2]}$ 。

Scholars did a lot of researches recently on the distribution of the compound planetary gears; some scholars analyzed the relationship between planetary gear's internal power flow and

This work was financially supported by the National Instrument Development Specific Project of China (Grant No. 2011YQ160002) system parameters ${ }^{[3]}$. Some built a experiment platform ${ }^{[4]}$. However, for vertical kneading drive train, the entire gear box is in the rotation, and the space between shafts is very narrow. Besides, the whole gear box is in the grease. What is more, gear's high speed rotation will also lead to a high temperature. According to these limitations, the installation of sensors is hard to realize. Furthermore, in order to seal and lubricate, the entire transmission case is firmly wrapped in the housing. Even if the torque sensors are installed, the torque signal is also very difficult to deliver. And the shaft of the high-speed rotation will cause the sensor connection disturbing. Due to the above reasons, the paper analyzes the relationship between distribution of toque and output torque, and uses simulation data obtained by FLUENT to calculate torque's quantitative results, which provides the design basis for small vertical mixer's transmission agent.

\section{TORQue ANALysis OF THE COMPOUND GEAR BoX}

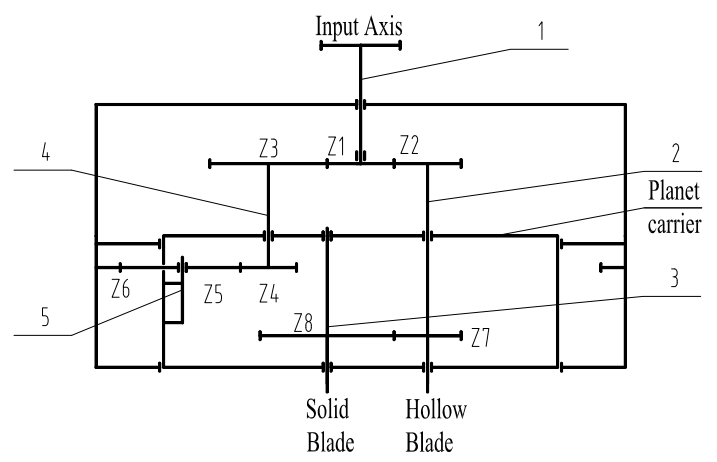

Figure 1. Transmission agent

1-Input Shaft I 2-Output Shaft II, connected to hollow blade 3-Output Shaft III, connected to solid blade 4-ShaftIV 5-Shaft V 
Power which comes from a motor, goes through the synchronous belt and the gear box, and then separates into two flows in $Z_{1}$. One way drives the entire planet carrier to move around $Z_{6}$ through $Z_{3}, Z_{4}, Z_{5}$, which drives the two blades to revolve. The other way follows $Z_{2}, Z_{7}$ and $Z_{8}$, to drive two blades to rotate. Gear $Z_{8}$ is connected to solid blade. Gear $Z_{7}$ is connected to hollow blade. Two blade's center and the revolution's center are not the same.

Gear box of the mixer is shown in Figure 1, which is formed by two planetary gear trains:

(1) Z1，Z2，Z7，Z8 and planet carrier form Gear train 1. It is a compound $\mathrm{K}-\mathrm{H}$ differential gear train.

(2) Z1, Z3, Z4, Z5, Z6 and planet carrier form Gear train 2. It is a compound $2 \mathrm{~K}-\mathrm{H}$ differential gear train.

When the gear box rotates uniformly, the sum of input and output torque is zero. For this system, a single-input multioutput system, the input torque $M_{I}$ separates into $M_{I 1}$ and $M_{I 2}$, which flow to revolution torque $M_{G}$ and rotation torque $M_{K}$ and $M_{S}$ respectively. $M_{n}$ represents the torque of Gear $Z_{n}$ or Shaft $n$.

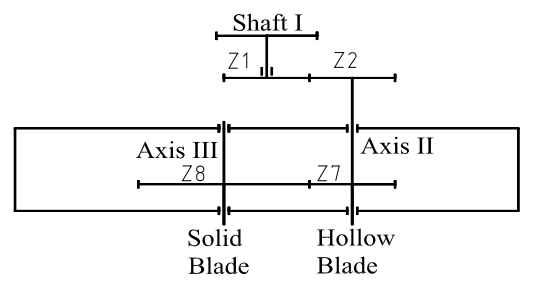

Figure 2. Gear Train 1

For Shaft III $M_{8}=M_{S}$

For Shaft II $\mathrm{M}_{2}=M_{7}+M_{K}$ And $\frac{M_{8}}{M_{7}}=\frac{Z_{8}}{Z_{7}}, \frac{M_{2}}{M_{I 1}}=\frac{Z_{2}}{Z_{1}}$

To summarize

$$
M_{I 1}=\frac{Z_{1}}{Z_{2}}\left(\frac{Z_{7}}{Z_{8}} M_{S}+M_{K}\right)
$$

$$
M_{I I}=M_{2}=\frac{Z_{7}}{Z_{8}} M_{S}+M_{K}
$$

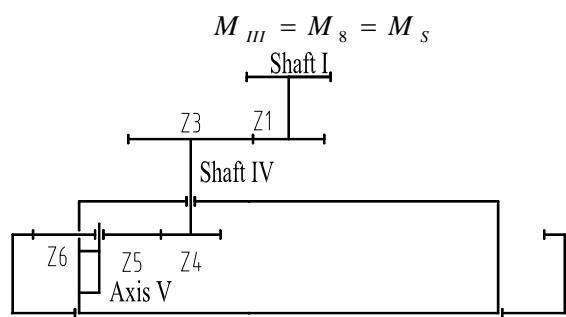

Figure 3. Gear Train 2
For Shaft IV $M_{3}=M_{4}$

For the planet carrier $M_{6}=M_{G}$

And $\frac{M_{3}}{M_{I 2}}=\frac{Z_{3}}{Z_{1}}, \frac{M_{4}}{M_{5}}=\frac{Z_{4}}{Z_{5}}, \frac{M_{5}}{M_{6}}=\frac{Z_{5}}{Z_{6}}$

To summarize $M_{I 2}=\frac{Z_{1} Z_{4}}{Z_{3} Z_{6}} M_{G}$,

$M_{I V}=M_{3}=M_{4}=\frac{Z_{4}}{Z_{6}} M_{G}, \quad M_{V}=M_{5}=\frac{Z_{5}}{Z_{6}} M_{G}$

For Shaft I

$$
\mathrm{M}_{\mathrm{I}}=\mathrm{M}_{\mathrm{I} 1}+\mathrm{M}_{\mathrm{I} 2}=\frac{\mathrm{Z}_{1}}{\mathrm{Z}_{2}}\left(\frac{\mathrm{Z}_{7}}{\mathrm{Z}_{8}} \mathrm{M}_{\mathrm{S}}+\mathrm{M}_{\mathrm{K}}\right)+\frac{\mathrm{Z}_{1} \mathrm{Z}_{4}}{\mathrm{Z}_{3} \mathrm{Z}_{6}} \mathrm{M}_{\mathrm{G}}
$$

$M_{K}$ and $M_{S}$ are the torque of solid blade and hollow blade to mix material and shear viscous fluid. $M_{G}$ contains two parts. One is the torque to make the gear box to revolve. The other is the torque of solid blade and hollow blade to move in the viscous fluid. The torque of solid and hollow blade is related to the speed of rotating and revolving, the viscosity of the material, the phrase of the blades and etc. The torque to make the gear box revolve is related to the structure, the lubrication and the material of gear box, which are ignored in this paper.

It is difficult to calculate and measure the value of $M_{K}, M_{S}$ and $M_{G}$. Therefore, we use the method of simulation to obtain the value. And then substitute the value in the relationship to get the torque distribution, which is useful to the design of vertical mixer.

\section{SIMULATION ANALYSIS}

Simulate the torque distribution of the minitype vertical mixer. Table I represents the key parameters of the vertical mixer. Figure 4 shows the position of two blades.

TABLE I. KEY PARAMETERS OF TWO BLADES

\begin{tabular}{|l|c|}
\hline \multicolumn{1}{|c|}{ Key parameter } & Value \\
\hline Height of blade /h $(\mathrm{mm})$ & 141 \\
\hline Effective height of material/ $\mathrm{h}$ ' $(\mathrm{mm})$ & 128 \\
\hline Inside diameter of the bowl/ $D(\mathrm{~mm})$ & 188 \\
\hline Minimum clearance/ $\sigma(\mathrm{mm})$ & 2.2 \\
\hline Center distance between two blades/ $C_{L}(\mathrm{~mm})$ & 67.2 \\
\hline Diameter of the blade/ $d \quad(\mathrm{~mm})$ & 94 \\
\hline $\begin{array}{l}\text { Distance between the hollow blade and the center } \\
\text { of the bowl/ } \alpha_{k}(\mathrm{~mm})\end{array}$ & 44.8 \\
\hline $\begin{array}{l}\text { Distance between the solid blade and } \\
\text { the center of the bowl/ } \alpha_{s}(\mathrm{~mm})\end{array}$ & 22.4 \\
\hline Ratio of offsetting between hollow blade and solid blade/ $\phi_{k, s}$ & 2 \\
\hline Diameter of base circle / $d_{b}(\mathrm{~mm})$ & 36 \\
\hline
\end{tabular}




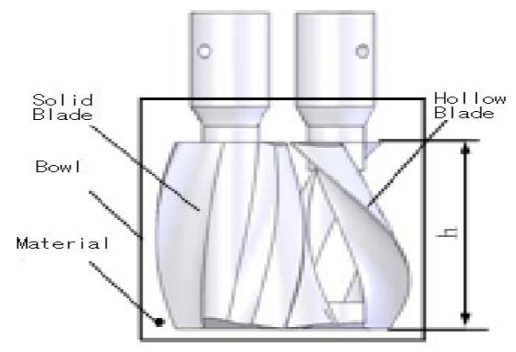

Figure 4. Position Of Two Blades

Load IGS exported from Solidworks into ICEM (The Integrated Computer Engineering and Manufacturing code for Computational Fluid Dynamics) ${ }^{[5]}$. Mesh the material, hollow blade and solid blade into unstructured tetrahedron. The result is shown in Figure 5. Then load the result into FLUENT for simulation.

In real production, the speed of hollow blade is the twice as much as that of solid blade, which is 20 to $30 \mathrm{r} / \mathrm{min}$. The ratio of revolving speed and rotating speed of the hollow speed is 1:11. The parameters of transmission agency are shown in Table II.

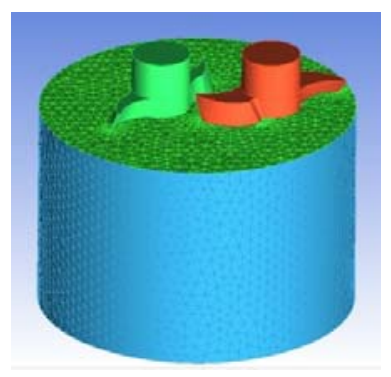

Figure 5. Meshing

TABLE II. PARAMETERS OF GEAR TRAIN

\begin{tabular}{|c|c|c|c|c|c|c|c|c|}
\hline Gear & $\mathbf{Z}_{1}$ & $\mathbf{Z}_{2}$ & $\mathbf{Z}_{3}$ & $\mathbf{Z}_{4}$ & $\mathbf{Z}_{5}$ & $\mathbf{Z}_{\mathbf{6}}$ & $\mathbf{Z}_{7}$ & $\mathbf{Z}_{\mathbf{8}}$ \\
\hline Number of teeth & 22 & 22 & 40 & 40 & 18 & 120 & 22 & 44 \\
\hline
\end{tabular}

The contact surfaces between two blades and fluid are set as moving boundaries. Kinematic equations of the moving surface and two blades are the same. The contact surfaces between inside-bottom wall of the bowl and the liquid are set as static boundaries.

Set the following assumption: the fluid is non-Newtonian fluid; the fluid is power-law fluid; the fluid is incompressible fluid; the fluid is full of the tube; flow field is unsteady state; flow field is isotherm; Flowing wall is thermal isolated and non-sliding; Reynolds Number is small; fluid is streamline flow; inertia force and gravity are much less than viscous force and can be ignored.

When the revolving speed is $0.273 \mathrm{rad} / \mathrm{s}(2.6045 \mathrm{r} / \mathrm{min})$, rotating speed of solid blade is $1.533 \mathrm{rad} / \mathrm{s}(14.325 \mathrm{r} / \mathrm{min})$, viscosity of the material is 200Pa`s, the result of simulation is shown in Figure 6. Chose 9 points of phrase: $20^{\circ}, 40^{\circ}, 60^{\circ}$, $80^{\circ}, 100^{\circ}, 120^{\circ}, 140^{\circ}, 160^{\circ}$, and $180^{\circ}$. Substitute in the relationship. The results are shown in Figure 7 and Figure 8.

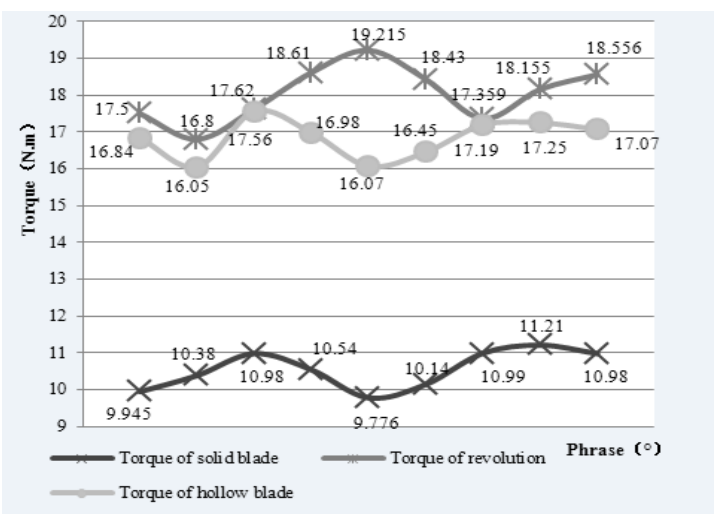

Figure 6. Torque Distribution Diagram (Solid Blade travels $180^{\circ}$ )

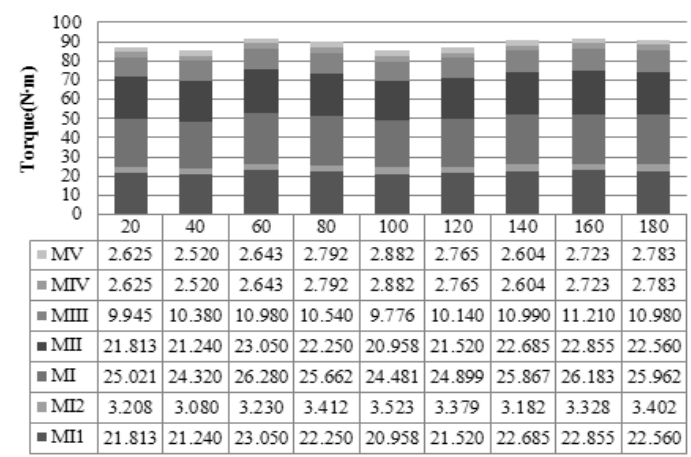

Figure 7. Torque Distribution

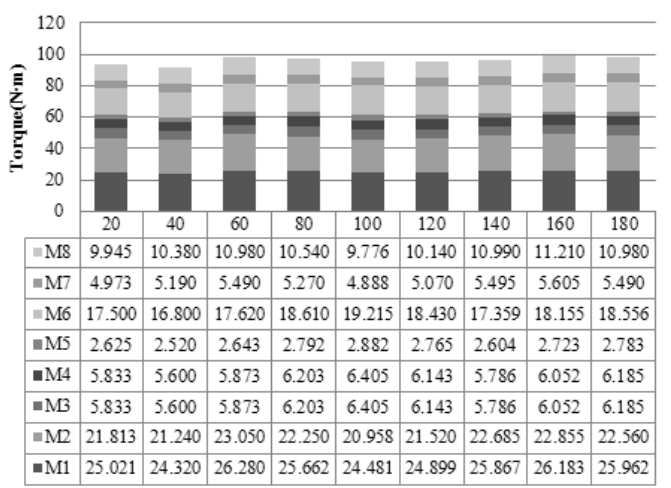

Figure 8. Torque of Gears

According to the simulation and calculation, the revolving and rotating speed of hollow blade and solid blade are changing with the phrase. The torque of solid blade and hollow blade are changing synchronously. And the revolving torque is change differently. Torque of hollow blade is 1.9 times as much as the torque of solid blade. The power is mainly used to drive Gear train 1 that is the rotation of solid blade and hollow blade, which taking up more than $80 \%$ energy. According the 
conclusion above, we can design these axis and gears. The torque of Axis II and Gear Z1, Z2 is large. In the process of design, they should be reinforced.

\section{REFERENCES}

[1] Yang Minjin, Reasearch on solid propellant 's mixing of vertival mixer[D], Huazhong University of Science\&Technology, 2008, pp. 1-3.

[2] Yi Chuanyun, Guan Yingbo, Study on the Torque of Kneading Mixer, Machinery \& Electronics, 2006(11), pp. 6-9.

[3] White G. Derivation of high efficiency two-stage epicycle gears[J]. Mechanism and Machine Theory, 2003(38), pp. 149-159.

[4] Xu Hailiang, Single loop planetary transmission theory and experimental research[D], Xi'an University of Technology, 2010, pp. 56-63.

[5] Li pengfei, Xuminyi, Proficient in CFD simulation and case of practical condition, Beijing: Posts \& Telecom Press, 2011, pp. 1-3. 